\title{
EXPERIMENTAL INVESTIGATION OF SENSIBLE THERMAL ENERGY STORAGE SYSTEMS IN BUILDING PILLARS
}

\author{
GIRI GOUTHAM, PURUSHARTH MAIR \& SREEKANTH MANAVALLA*
}

School of Mechanical Engineering, Vellore Institute of Technology Chennai Campus, Tamil Nadu, India

\begin{abstract}
This work presents the experimentally carried out performance investigation of three lab-scale solid sensible heat storage (SHS) models. The models analysed are of shell-and-tube type configuration, in which the SHS material is placed in the shell region and the heat transfer fluid $(\mathrm{HTF})$ is allowed to pass through the tubes. Thermal performances such as complete and effective charging/discharging times of three different models viz. Cuboid shaped concrete block with concentric arrangement of Copper tubes (termed as M1), Cuboid shaped concrete block with staggered arrangement of Galvanized Iron tubes (termed as M2) and Cylinder shaped concrete block with concentric arrangement of Galvanized Iron tubes (termed as M3) designed for a storage capacity of $21.2 \mathrm{MJ}$ each are studied. The temperature difference between the heat transfer fluid (HTF) and the storage model is fixed at $30^{\circ} \mathrm{C}$
\end{abstract}

KEYWORDS: Thermal Energy Storage, Sensible Heat Storage, Buildings, Concrete, Metal Tubes

Received: Jun 09, 2020; Accepted: Jun 29, 2020; Published: Aug 06, 2020; Paper Id.: IJMPERDJUN2020657

\section{INTRODUCTION}

Energy resources are highly significant with regards to monetary advancement of the nation. With the developing industrialisation, technology is rapidly moving towards automation, and the advancement of transportation division, the interest for energy storage and conservation is expanding gradually. The general trend of moving away from conventional energy source and increasing energy conservation awareness has stepped up the emphasis on investigations related to the range of applications and materials used to store energy with an aim to increase the storage and utilization capacity at the lowest cost, Gilet al.[1]. A Thermal energy system predominantly stores heat as sensible and/or latent energy in a substance. In a Thermal Energy Storage, the heat storage material also called as phase change material (PCM) undergoes a phase transformation for storing/releasing the heat. In thermochemical TES, the heat energy is stored/released due to the reversible chemical reactions occurring between the reactants/reactive components. Sensible heat storage (SHS) materials are highly thermal conductive than PCMs. Further, PCMs are highly corrosive in nature. Hence, PCMs cannot be used successfully for long-term TES applications, Mawire et al.[2]. Solid materials such as cast steel, stone, rock, sand, concrete and ceramic have usually been selected as sensible heat storage media depending on the required temperature range and specific application (R. Boonsu et al.,2016). Chiteka [4] and Howiket. al. [5] conducted experiments on concrete storage systems. Suarez et. al. [6] carried out modelling studies to understand the transient behaviour of storage systems. Alonso et. al. [7] used composite storage material in their experimental studies. Laing et. al. [8] applied thermal energy storage methods for solar thermal power plants. Vigneshwaranet. al. [9] and Rao et. al. [10] conducted experimental as well as computational studies on cast steel sensible heat storage systems. 
The TES system using concrete as the sensible heat storage media is usually implemented by embedding the pipes heat exchanger in concrete to transfer thermal energy to or from the heat transfer fluid, air, and synthetic oil. The advantages of using a concrete system include the low cost of the thermal storage media, the high heat transfer rates into and out of concrete, the ease of handling of the material, the availability of the material, and uncomplicated processing. This study investigates the performance of a sensible thermal energy storage system using concrete and metal tubing with water as the working fluid.

\section{EXPERIMENTAL SETUP}

Initially, the dimensions of the tubes and volume of the storage material have been established using fundamental energy balance calculations. Parameters such as material HTF tube, arrangements of HTF tubes, flow rate of HTF and shape of the model are varied. The significant parameters considered in the structure of SHS framework are specialized properties, cost effectiveness and ecological effects. The structure strategies associated with the improvement of SHS models are given underneath:

- Cylinder Outer body with concentric tubes with Fins.

- Cuboidal Outer body with Concentric Tube $(15 \mathrm{~mm})$ arrangement.

- Cuboidal Outer body with Staggered Tube arrangement.

- Cuboidal Outer body with two U-Tube arrangement.

- Cylindrical Outer body with concentric tube arrangement.

Each concrete block behaves like a thermal battery module, and multiple combination of these modules can be hydraulically connected to form a thermal battery system.

In the experimental study, the volume of the sensible storage material, using the parameters we have given the theoretical treatment to one of the possible model. By using steady state equation for required raise in the temperature of the concrete block, evaluating the mass of water and time taken to raise the temperature of the heat transfer fluid. For a pillar length of $1.5 \mathrm{~m}$ and $20 \mathrm{~cm}$ diameter, the mass was obtained as $108 \mathrm{~kg}$, heat to be transferred to raise the temperature by $20^{\circ} \mathrm{C}$ is $2166 \mathrm{~kJ}$, energy to be transferred to water to carry this heat is $9196 \mathrm{~kJ}$, and for a $4 \mathrm{~kW}$ heater, it would take about 40 minutes for the required energy transfer.

The experimental setup is shown in Figure 1 below. With the help of a heat gun and a couple of hose clamps, we were able to establish a successful connection between the Copper tubes and the EPDM Heat Resistant Rubber Water Hose (Black tubes in the image below). Furthermore, the EPDM Heat Resistant Rubber Water Hose were not very flexible which makes it difficult to work with them and did not allow us to establish an ideal ergonomic setting for the experimental setup. To counter this issue, we had to change the current fittings and tubes used in setup number one to a more ergonomic variant of the setup. To accomplish a more ergonomic and feasible experimental setup we used nipples for the tubes along with multiple GI fitting ( $\mathrm{T}$ joints, Elbow joints) and alloy flexible tubes (Geyser pipes) which made our new setup fool proof against the above stated issues. In addition, during the experimental runs, we encountered a few leaks due to collection of steam inside the setup but with the help of M-seal and Teflon tape, all of these issues were taken care of. 
A total of three pillars were constructed, two of them in cuboid shape with concentric and staggered arrangement of tubing and a Cylinder with Concentric arrangement of tubing. To construct the Cylinder cuboid we used an ABS sheet to make a mould in the shape of a cylinder with a base made of wood.

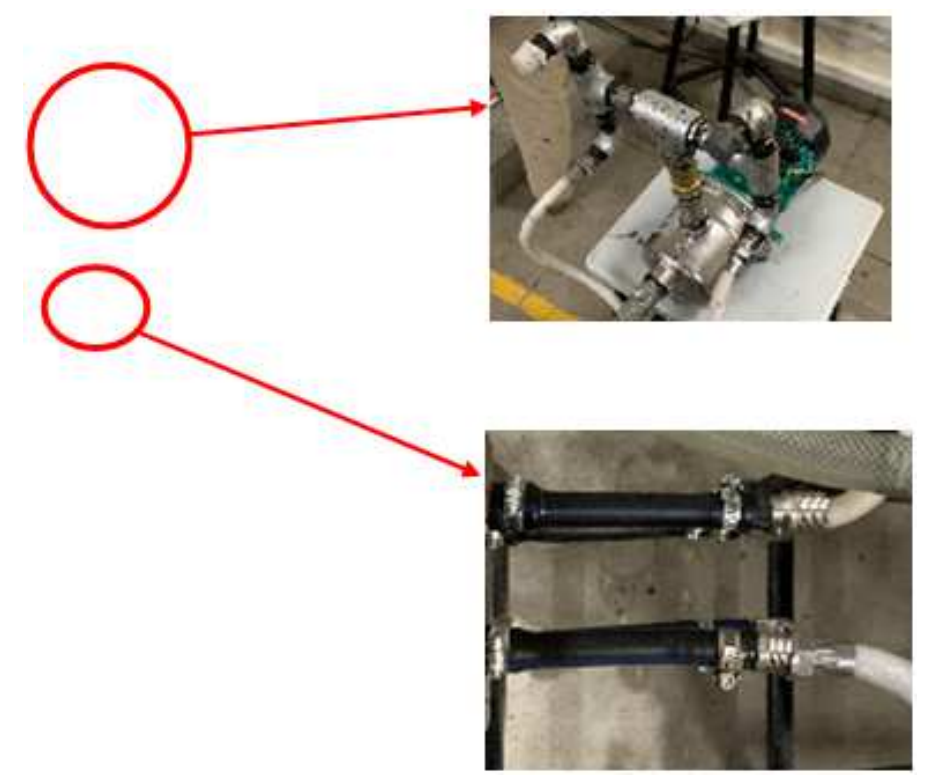

Figure 1: Experimental Facility.

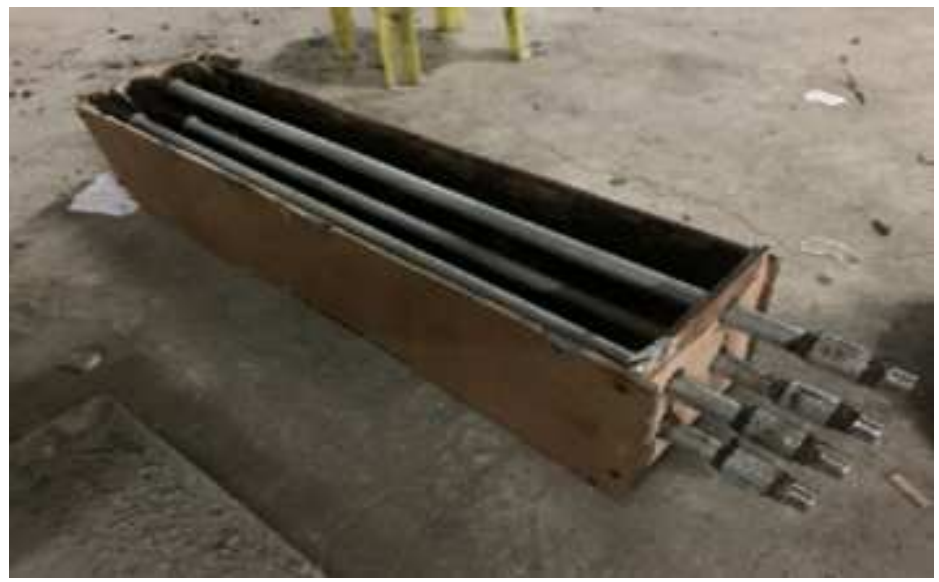

Figure 2: Pillar Being Cast with Tubes in Place.

Figure 2 shows an important stage before casting the pillars with concrete. It can be seen that the tubes had to be placed in the mould before pouring concrete. Figure 3 shows the pillar after casting, but before curing is complete. The pillars are allowed to cure for two weeks duration and they have been adequately watered during this period. 


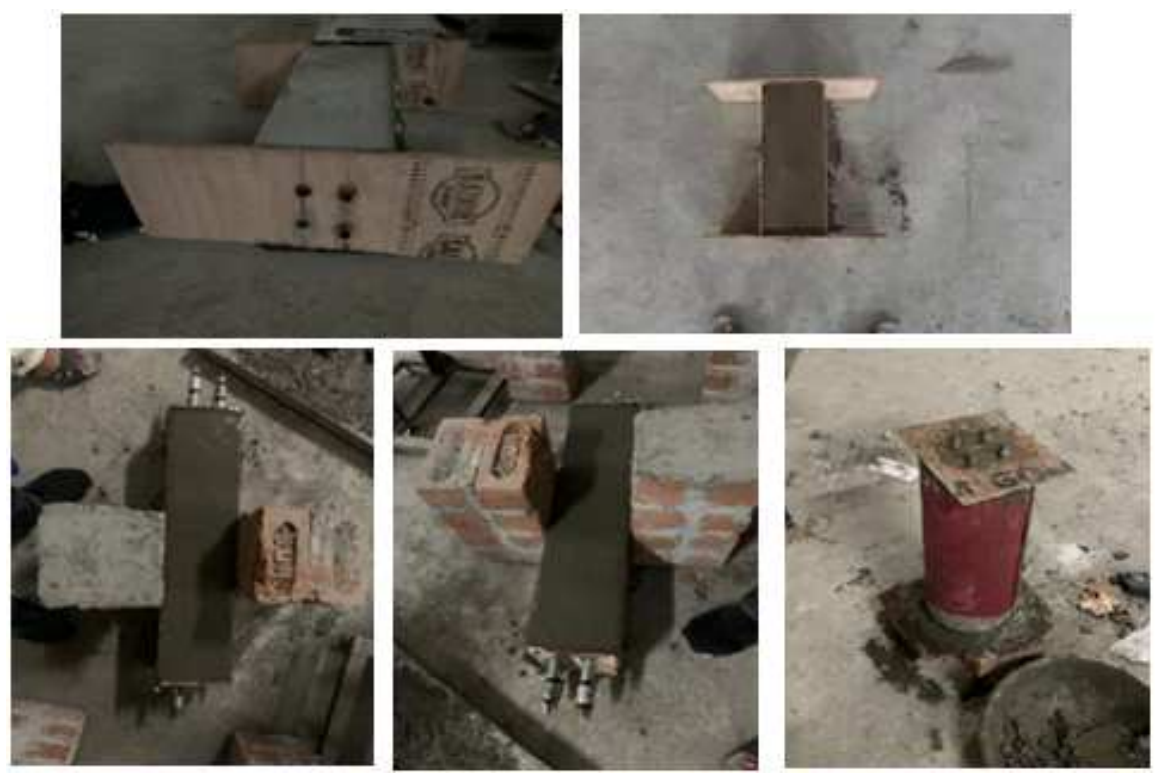

Figure 3: A View of the Pillars After Casting.

\section{EXPERIMENTAL PROCEDURE}

The Main objective of constructing the experimental setup and the pillar systems is to determine the most efficient model out of these pillar types and that is accomplished by comparing them against different parameters such as discharging times, charging times, and Peak temperatures reached at probe end and at the surface of the pillar surface. Therefore, with accordance with our objective for the project, we decided upon following certain steps and practices for conducting our experimental runs on the pillar systems. The complete procedure is mentioned below segregated into the following steps:

- The First step is to prepare the Experimental setup by attaching the 4 separate Alloy Flexible Pipes to the nipples on the Copper and GI tube ends inside the pillars.

- Meanwhile we need to start the heating of the water placed inside the storage tank at a temperature of $60^{\circ} \mathrm{C}$.

- To ensure the entire volume of the water tank is evenly heated, constant stirring and repetitive temperature checks need to be conducted.

- Now to check if the system is leak proof, we need to keep an open eye for all possible leakages in a test run, which lasts for about 1-2 minutes wherein we pump water and check all possible connections for any leakage.

- In case of any leakage, we use Teflon Tape to tighten the connections and completely fool proofing the setup.

- Also before proceeding with the experimental run, we need to check that the probes are inserted in the designated positions on the pillar surface.

- Now once the water has reached $60^{\circ} \mathrm{C}$, we start the pump and the water begins to flow.

- Now we adjust the flow rate with the help of the ball valve.

- Now with the help of MS Excel we tabulate the temperature of the inlet, outlet and at the various positions where probe is inserted.

- With the help of the digital box, the associated temperatures are noted at each location after every 10 minutes. 
- After 90 minutes, we stop the setup after taking the final reading.

- Now the next set of experiment is conducted with varying the position of the ball valve giving us a different flowrate this time.

- The similar procedure takes place for this setup from step number 2 to 11 .

\section{RESULTS AND DISCUSSION}

Experimental study was conducted for three models M1, M2 and M3 in which performance parameters such as Charging rate, discharging rate and efficiency were assessed out by varying HTF flow rates and orientation.

- M1: Concrete Cuboid with Copper tubes in concentric arrangement

- M2: Concrete Cuboid with GI tubes in staggered arrangement

- M3: Concrete Cylinder with GI tubes in concentric arrangement

Initially the models are observed to attain room temperature (same as that of the lab) at around $300 \mathrm{~K}$ and effectively the HTF is raised to temperature around $330-350 \mathrm{~K}$. The fluid flows through the tubes with a constant velocity without any leakages for a set time period until the model attains stable or overall average temperature throughout the model. In this study models of equivalent heat storage capacity of 21.6 MJ are fabricated, which are M1, M2 and M3. The charging time of the sensible heat storage model is one of the key performance assessments as it is directly related to heat storage characteristic of the model. Figure 4 presents the variation of average temperature of M1, M2, M3 during the charging process. It is observed that in model M1 the rise in temperature in phase one (0-40 min) is higher as compared to the (40-90 $\mathrm{min})$ this trend is evident in the literature, Chiteka and Enweremadu [4].

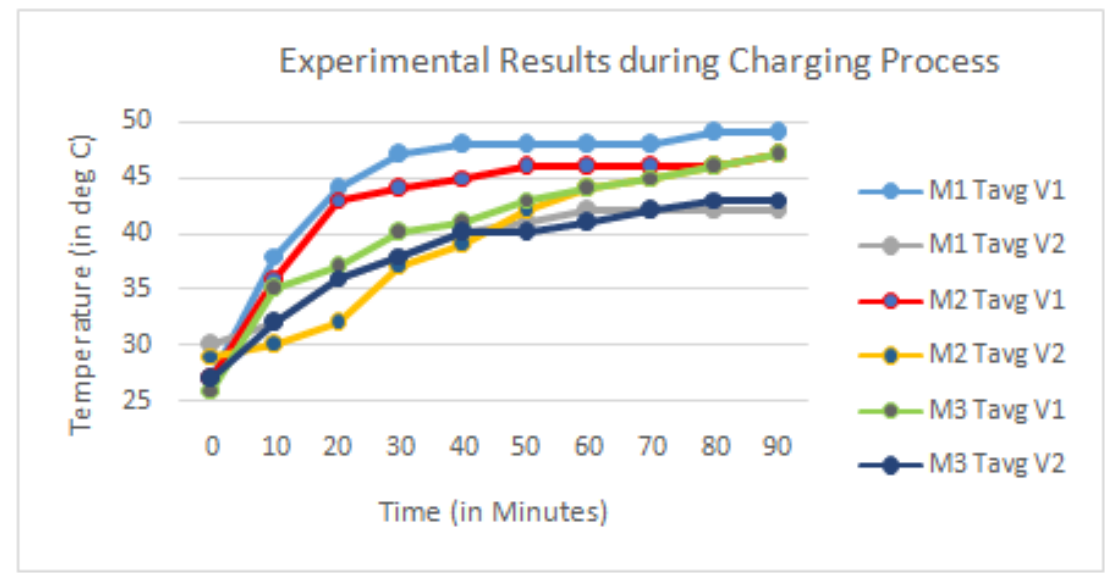

Figure 4: Transient Temperature Distribution.

It is also observed that between M1 (copper tube) and M2/M3 (galvanized iron) that M1 model are having better performance. This is achieved because copper material having better thermal properties (thermal conductivity copper -385 W/M-K,GI-59 W/M-k) that's why compared to GI overall heat transfer from the tubes to the sensible heat storage material is achieved rapidly by copper tubes. In Graph (8.1), the velocity V1 is $0.02 \mathrm{~m} / \mathrm{s}$ and V2=0.01 m/s. Compared to velocity V2, velocity V1 curves is having sharp rise, which in turn takes minimum time $1800 \mathrm{~s}$ to achieve stability for the model $\mathrm{M} 1$ at velocity $\mathrm{V} 1=0.02 \mathrm{~m} / \mathrm{s}$, and the effective charging time of M1, M2, M3 model is $40 \mathrm{~min}, 50 \mathrm{~min}$ and $60 \mathrm{~min}$ respectively. 
Sensible heat storage materials in general have low thermal conductivity such as concrete, mineral rock, ceramics etc., which in turn take more time to discharge due to poor heat transfer rate between the sensible storage material and the heat transfer fluid. Whereas M1, M2, M3 materials have attained average temperature between $\left(49-42^{\circ} \mathrm{C}\right)$, and heat transfer fluid flows at a temperature $\left(25\right.$ to $\left.27^{\circ} \mathrm{C}\right)$.

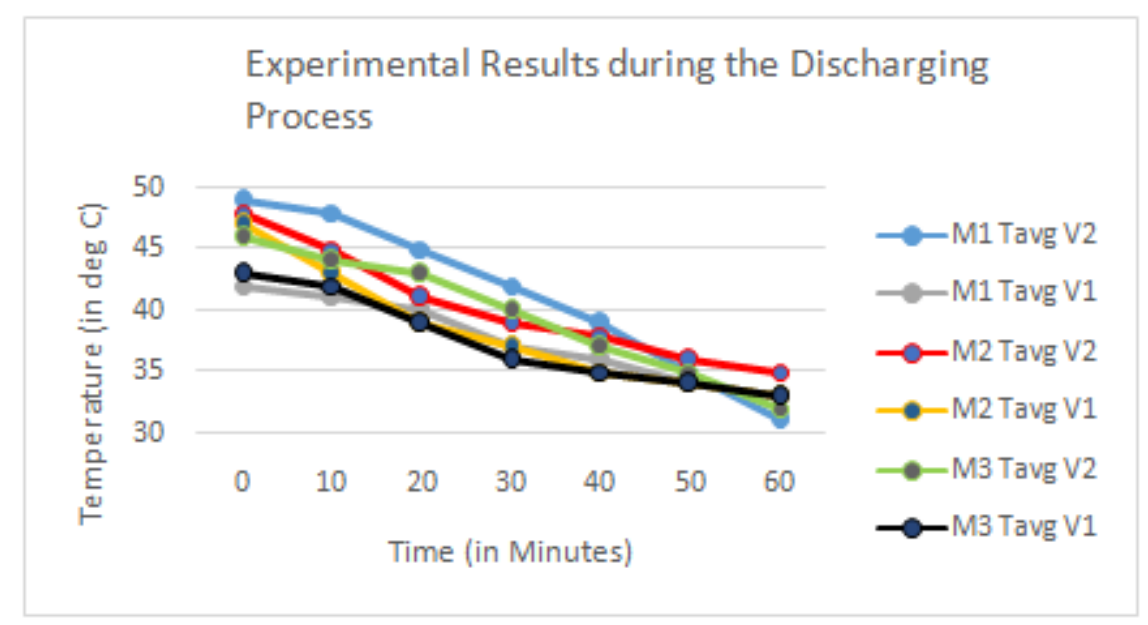

Figure 5: Temperatures during Discharging Process.

There is an effective quench in the curves in all the models M1, M2, M3 between (0-20 min). This is due to the higher heat transfer potential present during the initial period, which steadily drops over a span of time. This reduction is mainly due to the drop in average temperature in the models. These models are said to be discharged when they attain the heat transfer fluid inlet temperature.M2 and M3 comparatively have faster discharge compared to the M1, which is due to the metallurgical advantage. In experimental aspect, the discharging is achieved when models reach the initial inlet temperature, but the pump runs continuously for the completion of the cycle of charging and discharging time due to which external heat is supplied from the pump.

Figures 6 to 8 show the characteristics of heat transfer fluid velocity on the effective charging rates of the concrete models M1, M2, M3 and also for understanding the influence of heat transfer fluid velocity on the charging rates. The average temperature of the models of two different velocities (V1=0.02, V2=0.01 m/s) were analysed. It is clearly evident, irrespective of the orientation or metallurgical behaviour, the influence of velocity of the heat transfer fluids has a proportionate impact on the charging rate. The higher the increase in the value of heat transfer fluid velocity as compared to lower velocity the chances of reaching the average temperature will be high. This may be because of availability of the higher value of convection heat transfer coefficient. The charging time for the M1 model and velocities $\mathrm{V} 1=0.02 \mathrm{~m} / \mathrm{s}$ and $\mathrm{V} 2=0.01 \mathrm{~m} / \mathrm{s}$ are around $70 \mathrm{~min}$ and $90 \mathrm{~min}$ the reduction in charging time in M1 model is around 29\%. Similarly, the M2 model, reduction in charging time is around $36 \%$ and the reduction in time in case of the M3 model is $32 \%$. 


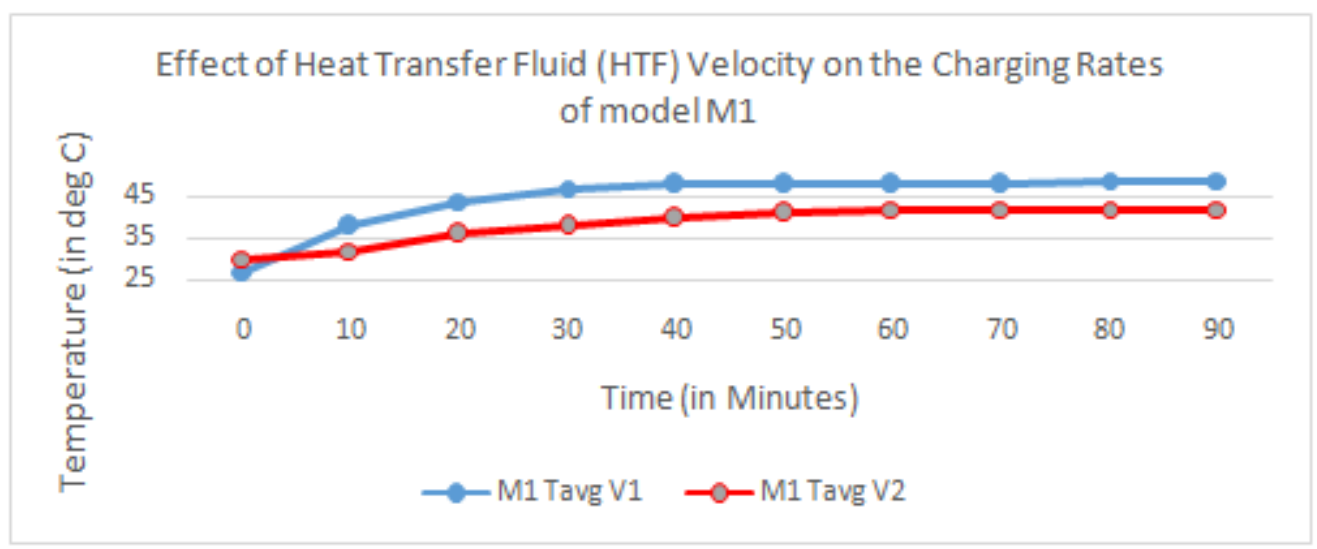

Figure 6: Effect of Fluid Velocity on Charging Rate of M1.

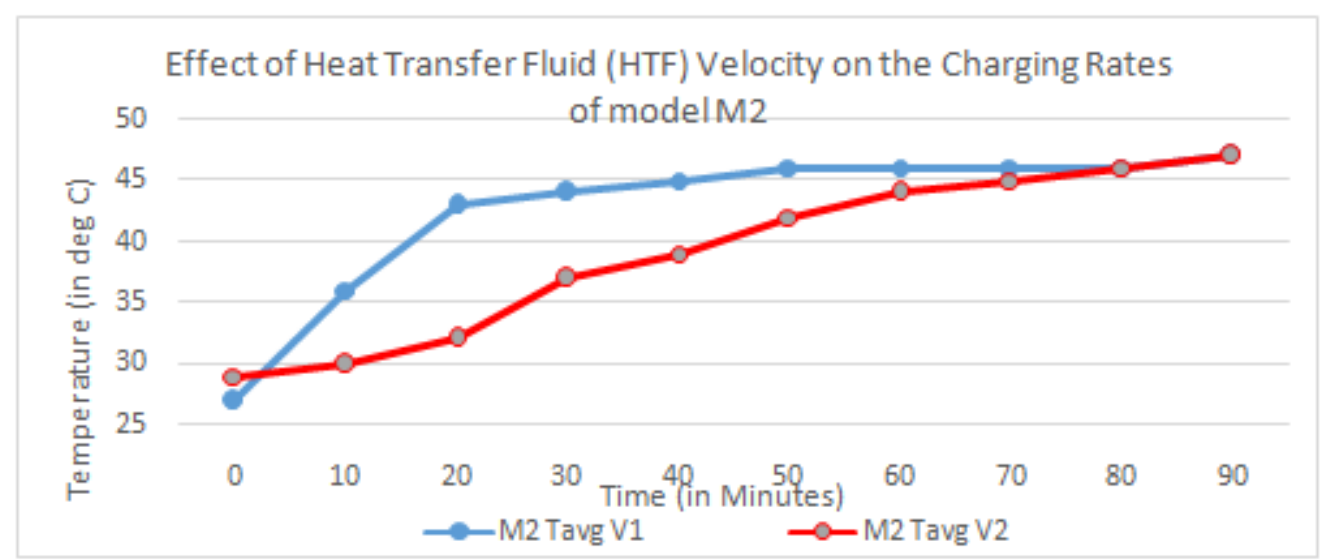

Figure 7: Effect of Fluid Velocity on Charging Rate of M2.

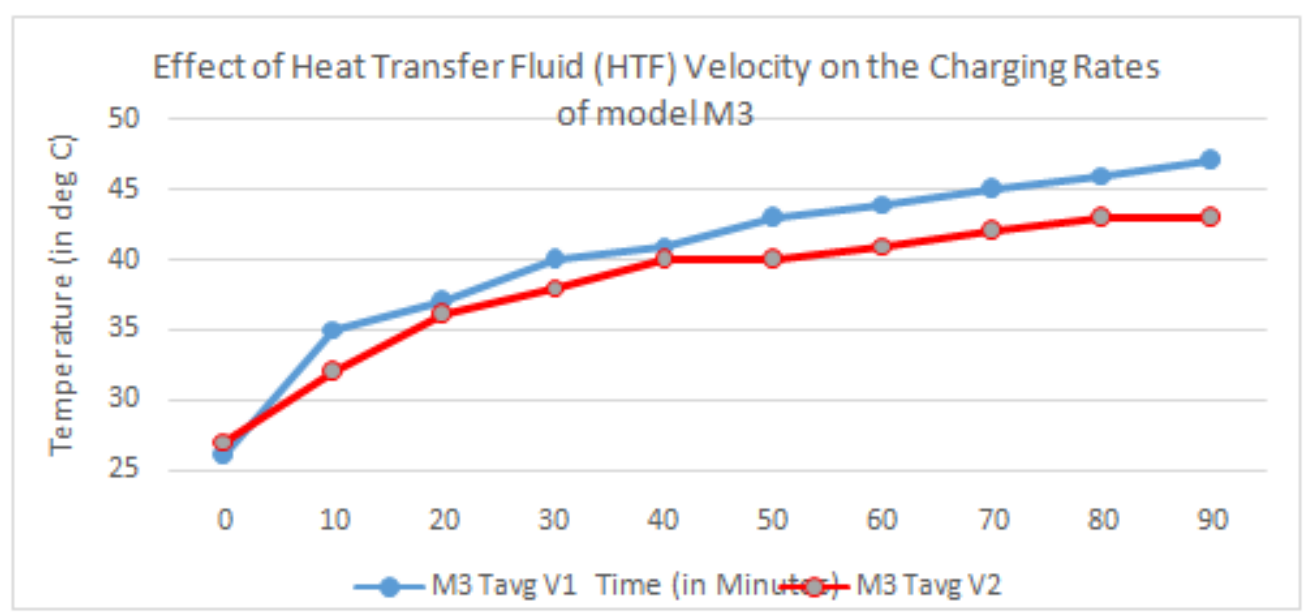

Figure 8: Effect of Fluid Velocity on Charging Rate of M3.

Figures 9 to 11 show the effect of heat transfer fluid velocity on the discharging rate of the concrete models M1, M2, M3. The higher the value of heat transfer fluids velocity is, faster the drop in temperature that can be noticed in the plots compared to the heat transfer fluid with lower velocity. 


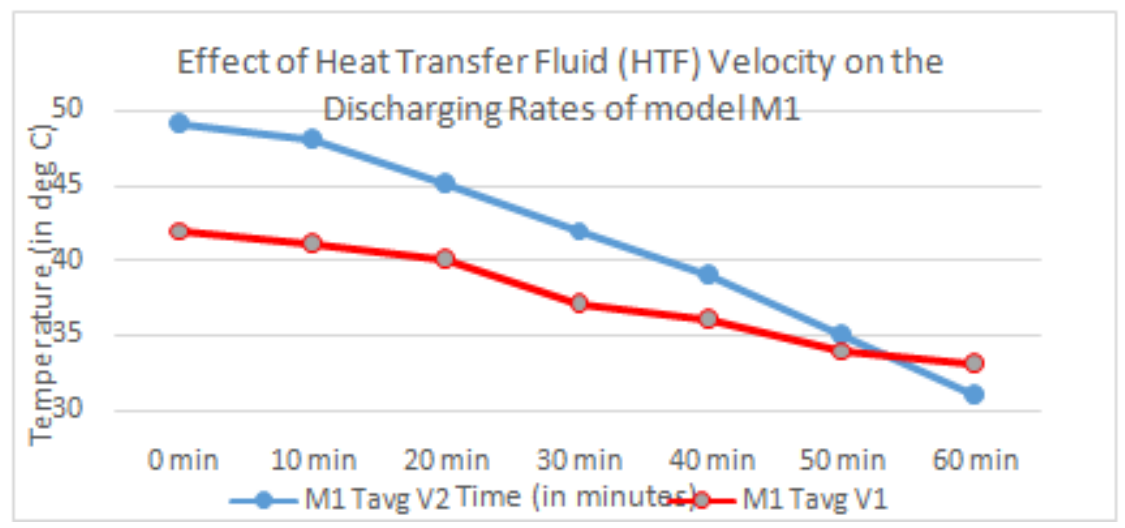

Figure 9: Effect of Velocity on Discharge Rate of M1.

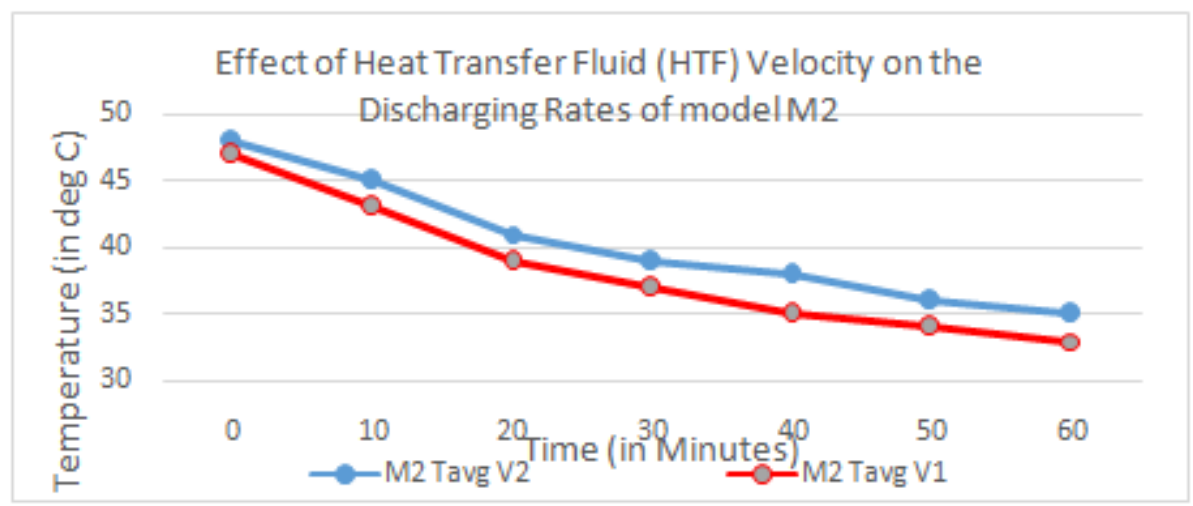

Figure 10: Effect of Velocity on Discharge Rate of M2.

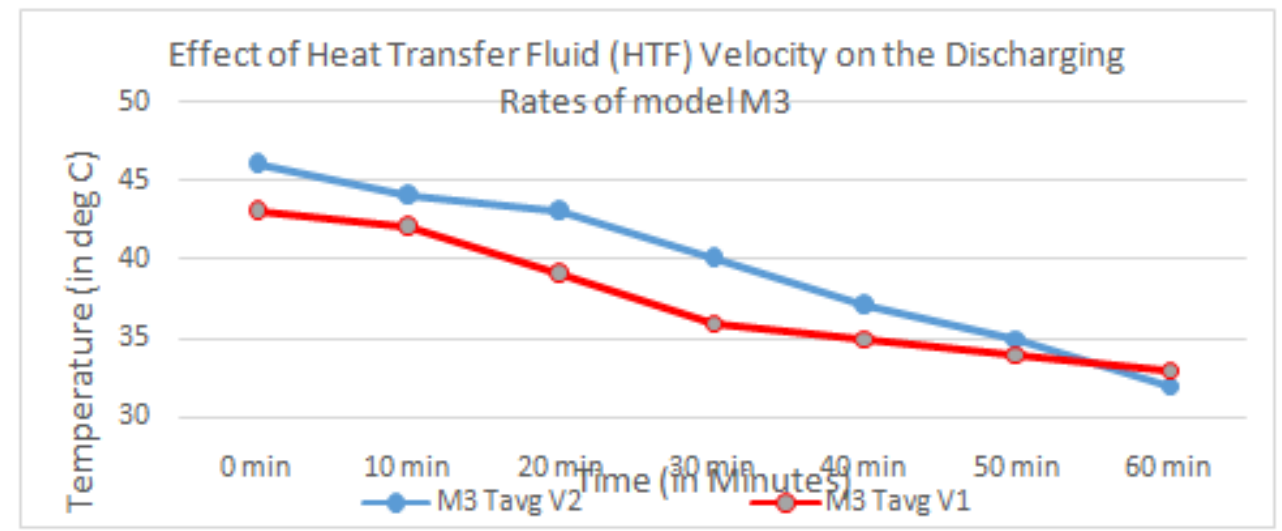

Figure 11: Effect of Velocity on Discharge Rate of M3.

The observed trend in the plots may be due the increase in forced convection present in the heat transfer fluid velocity. In most of the case the temperature has not reached the initial average inlet temperature of the heat transfer fluid, this may be because of the fluid reaching its saturation in the lab condition or maybe due to external heat addition in the heat transfer fluid due to the pump. In comparison with all the models the effective discharging time for model M1, M2, M3 are $50 \mathrm{~min}, 40 \mathrm{~min}$ and $45 \mathrm{~min}$ respectively. Out of these, M2 has faster discharging capacity due to the orientation of tube, which is arranged in staggered fashion. 


\section{CONCLUSIONS}

- Experimental study was carried out on the sensible storage models M1, M2, M3 of equivalent heat storage capacity 21.2 MJ are carried out during charging and discharging process. Performance parameters such as complete charging and discharging rate are evaluated.

- Which amongst the three pillars takes minimum period to achieve stability, the effective charging time of M1, M2, M3 model is $40 \mathrm{~min}, 50 \mathrm{~min}$ and $60 \mathrm{~min}$.

- As velocity of the heat, transfer fluid increases faster the rate of heat transfer. As depicted at velocity $0.02 \mathrm{~m} / \mathrm{s}$ compared to velocity $0.01 \mathrm{~m} / \mathrm{s}$ in all the models highlighted reduction in time taken for charging which is $29 \%$, $36 \%$ and $32 \%$.

- The effective discharging time for model M1, M2, M3 are $50 \mathrm{~min}, 40 \mathrm{~min}$ and $45 \mathrm{~min}$ respectively. Out of these, M2 has faster discharging capacity due to the orientation of tube, which is arranged in staggered fashion.

- M1 has recorded a peak temperature of $56^{\circ} \mathrm{C}$, which is achieved during simulation and $49^{\circ} \mathrm{C}$ during the experimental run.

- The current experimental and simulation of the models may be useful in the design and development of largescale SHS units, which can be integrated with the real time solar thermal power plants with an upgradation in the temperature range.

- Additionally, the studies presented here may also be helpful in building efficient hybrid storage systems, which comprises both sensible, and latent heat storage system

\section{REFERENCES}

1. Gil, A., Medrano, M., Martorell, I., Lázaro, A., Dolado, P., Zalba, B. and Cabeza, L.F., 2010. State of the art on high temperature thermal energy storage for power generation. Part $1-$ Concepts, materials and modellization. Renewable and Sustainable Energy Reviews, 14(1), pp.31-55.

2. Mawire, A., McPherson, M., Van den Heetkamp, R.R.J. and Mlatho, S.J.P., 2009. Simulated performance of storage materials for pebble bed thermal energy storage (TES) systems. Applied Energy, 86(7-8), pp.1246-1252.

3. Kidiyoor, Abhilash, and Kripa M. Suvarna. "A Study on Performance of Solar Water Heater Using Lauric Acid-Water as Thermal Storage System."TJPRC: International Journal of Heat and Mass Transfer (TJPRC: IJHMT) 1. 1, Jun 2016, 9-14

4. Boonsu, R., Sukchai, S., Hemavibool, S. and Somkun, S., 2016. Performance analysis of thermal energy storage prototype in Thailand. Journal of Clean Energy Technologies, 4(2), pp.101-106.

5. Chiteka, K. and Enweremadu, C., 2018. Evaluation of a concrete-graphite hybrid mixture for low-cost thermal energy storage material. Cogent Engineering, 5(1), p.1538490

6. Hoivik, N., Greiner, C., Barragan, J., Iniesta, A.C., Skeie, G., Bergan, P., Blanco-Rodriguez, P. and Calvet, N., 2019. Longterm performance results of concrete-based modular thermal energy storage system. Journal of Energy Storage, 24, p.100735.

7. Senthil, R., and M. Cheralathan. "Simultaneous testing of a parabolic dish concentrated PCM and non-PCM solar receiver." International Journal of Mechanical and Production Engineering Research and Development 7.6 (2017): 79-85. 
8. Suárez, C., Pino, F.J. and Guerra, J., 2020. A new simplified model for the unsteady response of concrete passive sensible TES systems. Journal of Energy Storage, 27, p.101042.

9. Alonso, M.C., Vera-Agullo, J., Guerreiro, L., Flor-Laguna, V., Sanchez, M. and Collares-Pereira, M., 2016. Calcium aluminate based cement for concrete to be used as thermal energy storage in solar thermal electricity plants. Cement and Concrete Research, 82, pp.74-86.

10. Senthil, R., and A. P. Nishanth. "Optical and thermal performance analysis of solar parabolic concentrator." International Journal of Mechanical and Production Engineering Research and Development 7.5 (2017): 367-374.

11. Laing, D., Bahl, C., Bauer, T., Fiss, M., Breidenbach, N. and Hempel, M., 2011. High-temperature solid-media thermal energy storage for solar thermal power plants. Proceedings of the IEEE, 100(2), pp.516-524.

12. Vigneshwaran, K., Sodhi, G.S., Muthukumar, P., Guha, A. and Senthilmurugan, S., 2019. Experimental and numerical investigations on high temperature cast steel based sensible heat storage system. Applied Energy, 251, p.113322.

13. Ayyad, Karim M., and Ines M. Baaziz. "A Green Approach for the Integration of Phase-Change Materials in Building Envelopes in Hot Arid Countries." International Journal of Civil Engineering, ISSN (2012): 2278-9987.

14. Rao, C.R.C., Vigneshwaran, K., Niyas, H. and Muthukumar, P., 2019. Performance investigation of lab-scale sensible heat storage prototypes. International Journal of Green Energy, 16(14), pp.1363-1378. 